\title{
重症頭部外傷に続発した尿崩症の循環動態
}

\author{
山下 雅知・坂本 哲也・佐々木 勝·堤 晴彦·有賀 徹・豊岡 秀訓 \\ 三井 香児
}

\section{Hemodynamics in Diabetes Insipidus Secondary to Severe Head Injury}

\author{
Masatomo Yamashita, Tetsuya Sakamoto, Masaru Sasaki, Haruhiko Tsutsumi, \\ Tohru ARUGa, Hidenori ToYOOKA and Koji MiI \\ Department of Emergency Medicine, University of Tokyo, Tokyo
}

\begin{abstract}
Hemodynamics of 7 diabetes insipidus (DI) patients secondary to severe head injuries were examined. In DI, without administration of Pitressin (vasopressin), systemic vascular resistance (SVR) and pulmonary vascular resistance (PVR) wcre markedly decreased while central venous pressure (CVP) and pulmonary capillary wedge pressure (PCWP) were rather low. In DI with administration of Pitressin ${ }^{\otimes}$, mean arterial pressure (MAP), SVR, and PVR were significantly increased. Cardiac index (CI) was decreased, but not significantly. Changes of CVP and PCWP were not significant. It seems that the elevation of MAP is caused by the increase of SVR and that Pitressin ${ }^{(1)}$ acts mainly on the resistance vessel, and not on the capacitance vessel.

Until recently, it was believed that physiological function of antidiuretic hormone (ADH) is diuresis and that the pressor effect of $\mathrm{ADH}$ plays no evident role under physiological conditions. But recent reports from several different laboratories indicate that ADH participates in the normal daily regulation of arterial pressure. The results of this study seems to support this hypothesis.

In DI patients, SVR is markedly decreased and the hemodynamics are rather hypervolemic. In this state, Pitressin ${ }^{\circledR}$ causes decrease of urine volume and increase of body fluid. In the administration of this drug, the possibility of edema of the brain, lung and other organs must be taken into consideration. Pitressin ${ }^{\mathbb{B}}$ also causes vasoconstriction of coronary vessels and increase of oxygen demand of myocardial muscle by increase of afterload due to elevated SVR and possibly myocardial ischemia.
\end{abstract}

Key words: diabetes insipidus, severe head injuries, hemodynamic profile, antidiuretic hormone, vasopressor

\section{I はじめに}

尿崩泟は抗利尿ホルモン $(\mathrm{ADH})$ の欠乏により低涱多尿 をきたしている状態で，病因から原発性上続発性に分けら れる。1965〜1974年の10年間の厚生省アンケート調查 ${ }^{12 \%}$ では，家族性 15 例 $(2.1 \%)$ ，特発性303例 $(42.5 \%)$ ，続発性 395 例 $(55.4 \%)$ である。続発性のうちでは兴腫瘍による症
例が192例でもっとも多く, ついで外傷42例，手術16例と なっている，また，脳死前後においても出現することが指 摘されてきた6).

今回我々は, 上記分類のらち外傷性原崩定患者, 寸なわ ち重症頭部外傷後にみられた尿崩症患者索対象とし，その 循環動態を調ぐ，與味ある結果を得たのでここに報告す る。

\section{東京大学救急部}

Address reprint requests to: M. Yamashita, M.D., Department of Emergency Medicine, University of Tokyo, 7-3-1 Hongo, Bunkyo-ku, Tokyo 113.

受稿 1984年3月7日 受理 1984 年5月18日 


\section{III研究対象および方法}

1981年 1 月から1984年 3 月までの 3 年間に当部に入院し た409例中，臨床上低張多尿をきたし尿崩症上考えられた 症例は 9 例みられた (Table 1)，5ち 7 例(〈症例 $1 \sim 7\rangle$ ) において, Swan-Ganz 肺動脈カテーテル法その他により 循環動態を調べた は Cardiac Output Computer 9520(Edwards Laboratories) により，心係数 ( cardiac index: $\mathrm{CI})=\mathrm{CO} /$ 体表面樍，全身 血管抵抗 (systemic vascular resistance: SVR $)=(\mathrm{MAP}-$ RAP) $/ C O \times 80$, 肺血管抵抗 (pulmonary vascular resistance: $\mathrm{PVR})=(\mathrm{MPAP}-\mathrm{PCWP}) / \mathrm{CO} \times 80$ として計算したーた だし MAP(mean arterial pressure $)=$ 平均動脈庄,

$\operatorname{RAP}($ right arterial pressure) $=$ 右房圧, PCWP ( pulmonary capillary wedge pressure) =肺動脈揳入圧，RAP は CVP ( central venous pressure) $=$ 中心静脈厌に等しい。詳細 は文献 10）を参照されたい。

外傷後にみられる尿崩症では，尿崩症の状態が一過性で あることも多く，その診断は難しいが，ここでは次の(1) (5) 診断基準とした。(1)時間尿量 $250 \mathrm{~m} l$ 以上が 3 時問以 上続くこと，(2)尿比重が1,010以下であること，(3)濃編力 以外の腎機能が正常であること, (4)ピトレッシン田(パー ク・デービス三共)投与により尿比重が1,010以上に上昇す ること，(5)マニトール，ラシックス，アルブミン製戍，造 影剂，高張ブドウ糖液など利尿効果を持つ薬剂を投与して いないこと、である。

ピトレッシンは静脈内持続投与または筋肉内注射により 投与し，投与後30分以上経過してから循澴動態を調べた。 ピトレッシン投与群および非投与群の各測定結果の統偍学

Table 1 Nine patients of diabetes insipidus

\begin{tabular}{ccll}
$\begin{array}{c}\text { Case } \\
\text { No. }\end{array}$ & $\begin{array}{c}\text { Age, } \\
\text { Sex }\end{array}$ & \multicolumn{1}{c}{ Disease } & \multicolumn{1}{c}{ Outcome } \\
\hline 1 & $15, \mathrm{~F}$ & $\begin{array}{c}\text { CC, ASH, basal fracture, } \\
\text { facial injury }\end{array}$ & brain death \\
2 & $65, \mathrm{M}$ & ICH & death \\
3 & $48, \mathrm{M}$ & SAH, ASH & brain death \\
4 & $52, \mathrm{M}$ & $\mathrm{CC}, \mathrm{ASH}$ & recovery \\
5 & $50, \mathrm{M}$ & $\mathrm{CC}, \mathrm{AEH}$ & brain death \\
6 & $48, \mathrm{M}$ & $\mathrm{CC}, \mathrm{ASH}, \mathrm{ICH}$ & recovery \\
7 & $50, \mathrm{M}$ & $\mathrm{CC}$, shock & brain death \\
8 & $21, \mathrm{M}$ & $\mathrm{CC}$, AEH, ICH & recovery \\
9 & $34, \mathrm{~F}$ & SAH & brain death \\
\hline
\end{tabular}

CC indicates cerebral contusion; ASH, acute subdural hematoma; ICH, intracerebral hematoma; SAH, subarachnoid hemorrhage; $\mathrm{AEH}$, acute epidural hematoma.
的な有意差は， $\mathrm{t}$-検定に上った。

また，上記診断基隼から外れる尿崩症を示さない脳死患 者14例についても同様の方法で循環動態を調べ，尿㴰怔患 者との比較の凟料とした。

\section{III 結 果}

尿崩症患者 7 例につき䛻環動態, 尿量, 尿比重, 使用薬 剂を測定した結果は Table 2 のごとくである.

これらの測定值をピトレッシン投与群と非投与群に分け

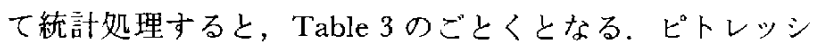
ン非投与群では PCWP, CVP ともにやや低值を示し，そ れにもかかわらずSVR, PVRが著明に低下していた。こ れに対しピトレッシン投与群では MAP, SVR, PVRが非 投与群に比し有意に增加し，CI はやや減少の傾向を示し た。すなわち，SVRの增加により MAP が堌加したこと になる。なお，ピトレッシン投与群では CVP や PCWP に有意の变化はみられなかった。

Fig. 1 にピトレッシン投与によるSVR, PVR 増加の 1 例(〈症例 1〉) 亦す。

一方, 脳死で尿崩症を呈さない症例の循環動態について は, SVR は641〜2,675 dyne $\cdot \mathrm{sec} \cdot \mathrm{cm}^{-5}(\mathrm{n}=14$, mean \pm SD $=1,162 \pm 543)$ 上一定の傾向はみられなかった(Table 4).

\section{IV 考 察}

正常な個体では，尿量増加により体液減少が起これば SVRの増加により血圧を維持しようとする．尿崩症の患 者では，PCWP とCVPがやや低值であるにもかかわらず SVR は逆に低下しており，正常な循環調節機構が失われ ていると考えられる，体液管理の面からも，たとえ泳量 とCVPだけ妾指標として輸液投与を施行したところ肺水 腫をきたした症例(〈症例 8$\rangle$ )も経験しており，尿崩症患者 の循環調節機構，特に血管平滑筋の制御に異常があること が示唆される.

ADH は vasopressin という別名が示す通り元米は vasopressor としての作用が注目された がが，その後はその生理 的作用汒抗利尿であり，生理的量の数百倍を投与しないと vasopressor としての効果を示さないと考えられてきだ.

しかし最近再び, ADHの vasopressor としての作用を見直 そうという考えがある。

Cowley $5^{3)}$ によれば，生理的濃度の ADH で正常のイ メでは血圧はあまり上昇しないが， baroreceptor denervated dog 屯たは decapitated dog においては血圧が著明に 上昇するという。すなわら， baroreceptor denervated dog では threshold sensitivity として11倍, pressor sensitivity と しては60〜100倍に達し, decapitated dog ではさらに感受 
Table 2 Hemodynamic profile, urine volume, urine gravidity, and administered drugs in 7 diabetes insipidus cases

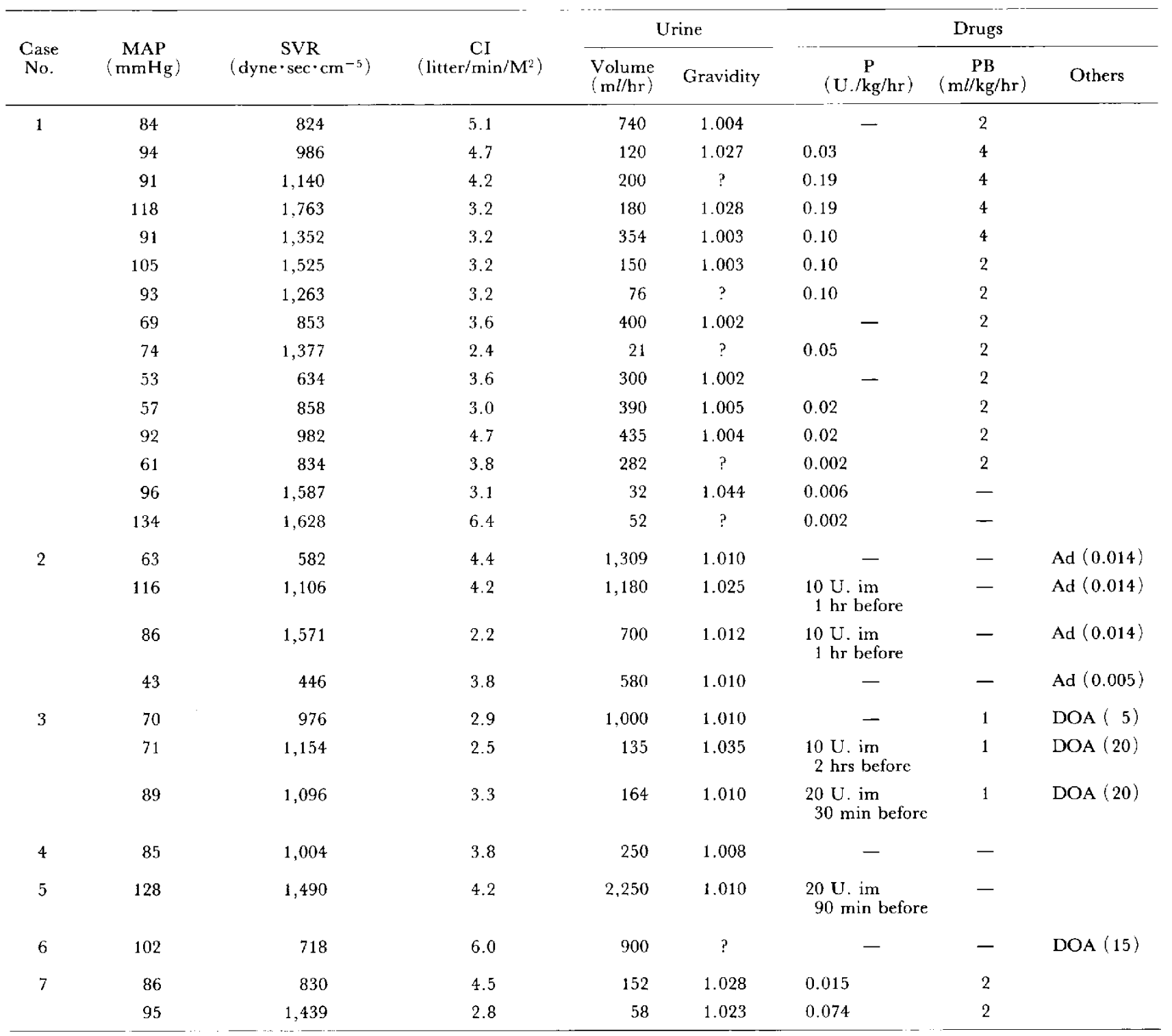

MAP indicates mean arterial pressure; SVR, systemic vascular resistance; CI, cardiac index; P, Pitressin ${ }^{8}$; PB, sodium pentobarbital; im, intramuscular injection; Ad, adrenaline $(\mathrm{mg} / \mathrm{kg} / \mathrm{hr})$; DOA, dopamine $(\mu \mathrm{g} / \mathrm{kg} / \mathrm{min})$.

性が上舁するという。彼らは、これらのイヌで著明な pressor 作用がみられる理由として background $の \mathrm{ADH}$ 裖 度が著明に低下しているためと考えている。これに比しそ れまでのイ又を使用した実験では，手術扝よび麻酔のスト レスが内因性の $\mathrm{ADH}$ 濃度をすでに上昇させており，しか も ADH-pressor dose-response function は exponential すでに ADH の pressor としての機能は plateauに達してい たと考えている。

この報告以外でも， baroreceptor system 在除去した麻酔
犬で mild hemorrhageの際に分泌されるADH 濃度は pressor 作用を引き起こすのに十分であるという報告》， hypophysectomy 後生理的量の ADH 投与で血圧が上:异す るという報告 ${ }^{4)}$ ，尿筋症のイヌで注出血に伴う血压低下が 起こりやすいという報告2), 自律神経異常患者は生理的星 のADHに対して著明な pressor response を示すという報 告 ${ }^{11) ， カ テ コ ー ル ア ミ ン の ~ p r e s s o r ~ e f f e c t ~}$ は生理的量の $\mathrm{ADH}$ 投与により增强するという報告2.31もあり，いずれ も ADH の正常個体における pressor 機能を示唆している. 
Table 3 Averaged hemodynamic profile of diabetes insipidus and Pitressin ${ }^{\circledR}$ administration

\begin{tabular}{|c|c|c|c|}
\hline & \multicolumn{2}{|c|}{ Mean $\pm S D$} & \multirow[b]{2}{*}{$t$ - test } \\
\hline & $\begin{array}{l}\text { Pitressin }(-) \\
\quad(n=10)\end{array}$ & $\begin{array}{l}\text { Pitressin }(+) \\
\quad(\mathbf{n}=19)\end{array}$ & \\
\hline HR (beats/min) & $90 \pm 25$ & $82 \pm 22$ & $P>0.20$ \\
\hline MAP $(\mathrm{mmHg})$ & $75.0 \pm 20.3$ & $93.5 \pm 20.4$ & $P<0.05$ \\
\hline MPAP $(\mathrm{mmHg})$ & $12.8 \pm 5.6$ & $14.4 \pm 6.1$ & $P>0.20$ \\
\hline PCWP (mmHg) & $7.4+4.9$ & $8.2 \pm 5.1$ & $P>0.20$ \\
\hline CVP $(\mathrm{mmHg})$ & $4.0 \pm 3.4$ & $5.4 \pm 4.9$ & $\mathrm{P}>0.20$ \\
\hline SVR (dyne $\left.\cdot \mathrm{sec}^{\prime} \mathrm{cm}^{-5}\right)$ & $777 \pm 186$ & $1,261 \pm 292$ & $P<0.01$ \\
\hline $\operatorname{PVR}\left(\right.$ dyne $\left.\cdot \mathrm{sec} \cdot \mathrm{cm}^{-5}\right)$ & $63.4 \pm 29.0$ & $96.2 \pm 36.1$ & $P<0.05$ \\
\hline $\mathrm{a}-\mathrm{vDO}_{2}(\mathrm{vol} \%)$ & $2.67 \pm 1.14$ & $2.64+1.00$ & $P>0.20$ \\
\hline $\mathrm{VO}_{2} / \mathrm{M}^{2}\left(\mathrm{~m} / / \mathrm{min} / \mathrm{M}^{2}\right)$ & $114 \pm 48$ & $96 \perp 30$ & $P>0.20$ \\
\hline $\operatorname{LVSWI}\left(\mathrm{gm} \cdot \mathrm{M} / \mathrm{M}^{2}\right)$ & $46.6 \pm 24.1$ & $52.3 \pm 21.3$ & $P>0.20$ \\
\hline PVSWI $\left(\mathrm{gm} \cdot \mathrm{M} / \mathrm{M}^{2}\right)$ & $6.2 \pm 3.5$ & $6.1=2.9$ & $P>0.20$ \\
\hline $\mathrm{CI}\left(\right.$ litter $\left./ \mathrm{min} / \mathrm{M}^{2}\right)$ & $4.2 \pm 0.9$ & $3.6=1.0$ & $P>0.10$ \\
\hline
\end{tabular}

HR indicates heart rate; MAP, mean arterial pressure; MPAP, mean pulmonary artcrial pressure; PCWP, pulmonary capillary wedge pressure; CVP, central venous pressure; SVR, systemic vascular resistance; PVR, pulmonary vascular resistance; a- $\mathrm{VDO}_{2}$, arteriovenous difference of oxygen; $\mathrm{VO}_{2} / \mathrm{M}^{2}$, oxygen consumption per $\mathrm{m}^{2}$ body surface area: LVSWI, left ventricular stroke work index; RVSWI, right ventricular stroke work index; $\mathrm{CI}$, cardiac index.

Table 4 Hemodynamic profile of brain death cases not showing diabetes insipidus

\begin{tabular}{|c|c|c|c|c|c|c|}
\hline \multirow[b]{2}{*}{$\begin{array}{l}\text { Case } \\
\text { No. }\end{array}$} & \multirow[b]{2}{*}{$\frac{\text { MAP }}{(\mathrm{mmHg})}$} & \multirow{2}{*}{$\begin{array}{c}\text { SVR } \\
\text { (dyne. } \\
\mathrm{sec}^{-} \\
\mathrm{cm}^{-5} \text { ) }\end{array}$} & \multirow{2}{*}{$\begin{array}{c}\text { CI } \\
(\text { litter } / \\
\left.\text { min/M } M^{2}\right)\end{array}$} & \multicolumn{3}{|c|}{ Drugs } \\
\hline & & & & $\underset{(\mathrm{m} l / \mathrm{kg}}{\mathrm{PB}}$ & $\begin{array}{c}\mathrm{DOA} \\
(\mu \mathrm{g} / \mathrm{kg} \\
/ \mathrm{min})\end{array}$ & Others \\
\hline 1 & 59 & 871 & 2.6 & 4 & 2 & \\
\hline 2 & 80 & 1,328 & 3.1 & 2 & 3 & \\
\hline 3 & 57 & 648 & 4.2 & - & 10 & \\
\hline 4 & 56 & 659 & 3.7 & - & 1 & \\
\hline 5 & 94 & 1,169 & 3.6 & - & 1 & \\
\hline 6 & 94 & 1,588 & 2.7 & - & 16 & $\operatorname{Ph}(0.03)$ \\
\hline 7 & 52 & 693 & 3.4 & - & 1 & $\operatorname{Ad}(0.0005)$ \\
\hline 8 & 44 & 641 & 2.8 & - & 15 & Nor $(0.01)$ \\
\hline 9 & 78 & 911 & 3.4 & 1 & - & \\
\hline 10 & 61 & 1,289 & 2.2 & - & 5 & $\operatorname{Nor}(0.005)$ \\
\hline 11 & 86 & 1,151 & 3.2 & - & 8 & \\
\hline 12 & 89 & 1,095 & 3.8 & 1 & - & \\
\hline 13 & 84 & 1,555 & 2.9 & - & 12 & \\
\hline 14 & 74 & 2,675 & 1.4 & - & 8 & \\
\hline
\end{tabular}

MAP indicates mean arterial pressure; SVR, systemic vascular resistance; CI, cardiac index; PB, sodium pentobarbital; DOA, dopamin; $\mathrm{Ph}$, phenylephrine $(\mathrm{mg} / \mathrm{kg} / \mathrm{hr}) ; \mathrm{Ad}$, adrenaline ( $\mathrm{mg} / \mathrm{kg} / \mathrm{hr})$; Nor, noradrenaline $(\mathrm{mg} / \mathrm{kg} / \mathrm{hr})$.
[No. 1]: $9 / 9$ 22:00 $\mathrm{Hrs}$

[No. 2] : 9/10 8:00 Hrs

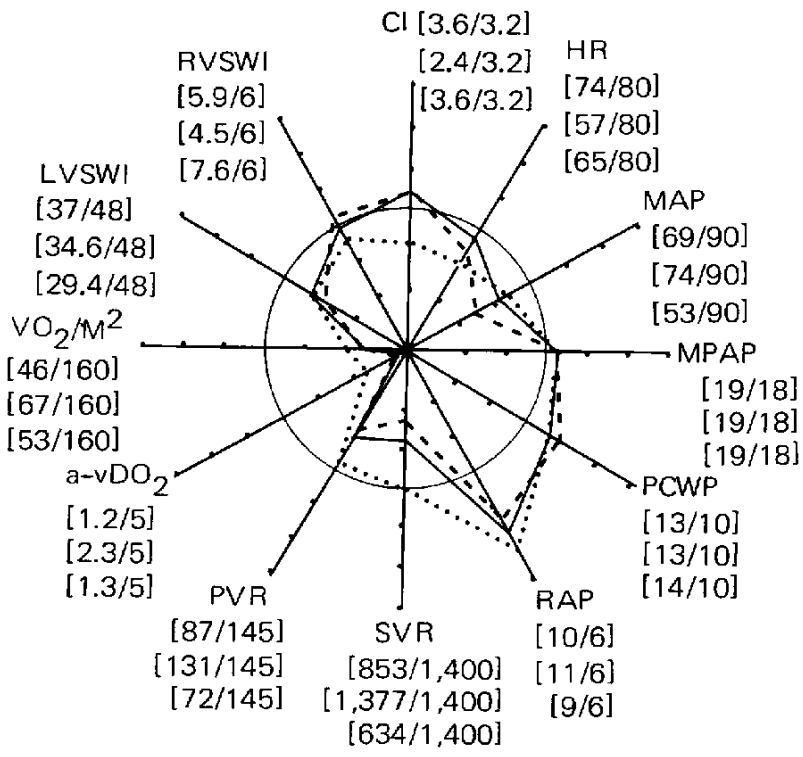

Fig. 1 Hemodynamic profile in Case 1 showing elevation of SVR and PVR by Pitressin. Pitressin ${ }^{3}$ was administered in No. 2 and was not administered in No. 1 and No. 3. Abbreviations are same as in Table 3. RAP is right arterial pressure and is equal to CVP. Numbers in the parentheses indicate observed value / normal value.

今回の測定では，ピトレッシン以外にもバルビタール， ドパミン，アドレナリンなど循環系に影響を与える薬用が 併用されている症例も多く，かつピトレッシンの投与濃 度，投与方法も種々であり，ピトレッシンの pressor 機能 を単独に解析するのは難しいが，ピトレッシン投与により SVR, PVR, MAP は有意に上昇し，一少CVPやPCWP には有意の变化はみられなかった。すなおち，CVP を指 標とする capacitance vessel一の影響は少なく，SVR を指 標と寸る resistance vessel への影響が著明であった。これ らの結果は, ADH がカテコールアミンや自律神経系とと もに正常個体に抢ける循環系制御の一端を担っているとい う考えを支持するものと思われる。

臨床的には，尿崩症患者ではSVR が著明に低下してお り，たとえば一過性と考えられる尿崩病患者に対してピト レッシンを投与せずに疗量やCVP, PCWP の值を指標と して輸液投与を行うと，兴や脯の浮腫をきた寸恐れがあ る.をた，この状態でピトレッシンを投与すると库量が急 激に減少して体液眝留が増長され，さらに浮腫が要化する 可能性もあるのでピトレッシン投与には注意が必要とな 
る，一方，冠動脈疾患の患者にピトレッシンを投与して狭 心症発作をきたしたという報告3,4! があるが，今回の結果 も示すように，ピトレッシン投与による冠動脈汉縮に加え て SVR 上昇のため後負荷が增加し，心筋の酸素需要量む 增加して心筀虚血を引き起こす可能性があるので，この点 でもピトレッシン投与には注意が必要である.

今後はさらに症例を增やし, ADH 濃度とpressor 機能 の does-response relationship 解析していきたいと考えて いる.

\section{$\mathrm{V}$ ま め}

1. 重症頭部外傷後にみられた尿崩症患者 7 例の循環動 態を Swan-Ganz 肺動脈カテーテル法その他により調ぐ た.

2. 尿崩症患者のピトレッシン非投与群では CVP, PCWP がやや低值を示し，それにもかかからずSVR， PVR が著明に低下していた，一方，尿崩症患者のピトレ ッシン投与群では非投与群に比し MAP, SVR, PVR が有 意に增加しており，CVPやPCWPには有意の变化はみら れなかった。すなわち，ピトレッシンの影響は capacitance vessel 一は少なく resistance vessel 几注著明であった.

3. 臨床的には, 尿崩症患者の体液管理をピトレッシン を投与せずに尿量やCVPにより施行すると脳や肺の浮腫 をきたす恐れがある。この状態でピトレッシンを投与する と急激な尿量減少により体液䝪留をきたし浮腫を増悪する 可能性があるので，ピトレッシン投与には十分な注意が必 要である，一方，ピトレッシン投与により冠動脈収縮が起 こる上に SVR 上昇により後負荷が増加して心筇酸素需要 増加が起こり，心笳虚血をきたす恐れむあるので，この点 にも留意すべきである。

\section{文献}

1）有賀 徹, 小野一之, 川原信隆, 佐々木勝, 堤 晴䖉, 豊 岡秀訓，三井香児，高倉公朋：重症脳不全の管理に扔ける循 環動態図の重要性. Neurol Med Chir (Tokyo) 23:860-866, 1983

2) Bartelstone HJ, Nasmyth PA: Vasopressin potentiation of cathecholamine actions in dog, rat, cat, and rat aortic strips. Amer $J$ Physiol 208: 754-762, 1965

3) Cowley AW Jr, Monos E, Guyton AC: Interaction of vasopressin and the baroreceptor reflex system in the regulation of arterial blood pressure in the dog. Circ Res 34: 505-514, 1974

4) Monos E, Koltay E, Kovach AGB: Adrenal blood flow and corticosteroid secretion: III. Effect of vasopressin on blood circulation and corticosteroid secretion in the dog before and after acute hypophysectomy. Acta Physiol Acad Sci Hung 31: 149-157, 1967

5) Oliver G, Schäfer EA: On the physiological action of extracts of pituitary body and certain other glandular organs. $J$ Physiol (London) 18: 277-279, 1895

6) Ouaknine GE: Bedside procedures in the diagnosis of brain death. Resuscitation 4: 159-177, 1975

7) Rocha E, Silva $\mathbf{M} \mathbf{J r}$, Rosenberg $\mathbf{M}$ : Release of vasopressin response to hemorrhage and its role in the mechanism of blood pressure regulation. $J$ Physiol (London) 202: 535-557, 1969

8) Sawyer WH: Neurophyscal hormones. Pharmacol Rev 13: 225277, 1961

9) Slotnik IL, Teigland JD: Cardiac accidents following vasopressin injection (Pitressin). JAMA 146: 1126, 1951

10）豊岡秀訓：ショック患者の手術上麻酔. 山村秀夫(監修). ショック・熱偈. 東京, 日本メディカルセンター, 1983, pp $84-91$

11) Wagner HN, Braunwald E: Pressor effect of the antidiuretic principle of the posterior pituitary on orthostatic hypertension. $J$ Clin Invest 35: 1412-1418, 1956

12）吉田 尚：尿崩症をめぐって，本邦臨床統計とその対策. 日臨 38: 2924-2928, 1980

〔別刷請求先：市113 東京都文京区本䐚7-3-1，東宗大学救急部， 山下雅知了 